CLINICAL STUDY

\title{
Second primary malignancies following thyroid cancer: a population-based study in Taiwan
}

\author{
Chang-Hsien $\mathrm{Lu}^{1,2,3, *}$, Kuan-Der Lee ${ }^{1,2,3, *}$, Ping-Tsung $\mathrm{Chen}^{1,2,3}$, Chih-Cheng Chen ${ }^{1,2,3}$, Feng-Che Kuan ${ }^{1,2,3}$, \\ Cih-En Huang ${ }^{1}$, Miao-Fen Chen ${ }^{2,3,4}$ and Min-Chi Chen ${ }^{5}$ \\ ${ }^{1}$ Department of Hematology and Oncology, Chang-Gung Memorial Hospital, No. 6, Chia-Pu Road, Putz City, Chia-Yi, Taiwan, ${ }^{2}$ Graduate Institute of \\ Clinical Medical Sciences, Chang-Gung University, Tao-Yuan, Taiwan, ${ }^{3}$ Chang Gung Institute of Technology, Tao-Yuan, Taiwan, ${ }^{4}$ Department of Radiation \\ Oncology, Chang-Gung Memorial Hospital, Chia-yi, Taiwan and ${ }^{5}$ Department of Public Health and Biostatistics Consulting Center, School of Medicine, \\ Chang-Gung University, 259 Wen-Hwa 1st Road, Kwei-Shan, Tao-Yuan 333, Taiwan
}

(Correspondence should be addressed to M-C Chen; Email: mcc@mail.cgu.edu.tw)

*(C-H Lu and K-D Lee contributed equally to this work)

\begin{abstract}
Objective: Most studies on second primary malignancies (SPMs) after primary thyroid cancer were conducted in USA or Europe. The discrepancy between SPMs in these studies could be attributed to geographical and ethnic heterogeneity. Thus, there is a clear need for another large-scale epidemiological study, particularly in Asian countries, to define the incidence and risk of SPMs in thyroid cancer survivors.

Design: A population-based study was conducted using the nation-wide database from Taiwan Cancer Registry between 1979 and 2006.

Methods: We quantified standardized incidence ratios (SIRs) and cumulative incidence of SPMs among 19068 individuals (4205 males and 14863 females) with primary thyroid cancer.

Results: A total of 644 cases (3.38\%) developed at least a SPM during 134678 person-years of follow-up. The risk for subsequent SPMs was significantly greater than that of the general population ( $\mathrm{SIR}=1.33$, 95\% CI 1.23-1.44). There was a greater risk of developing major salivary glands, nasopharyngeal, lung, thymus, breast (females), bladder, and brain cancers, and leukemia and lymphoma. We observed that the risk was highest within the first 5 years of diagnosis of thyroid cancer $(\mathrm{SIR}=5.29,1.68$, and 0.68 for $\leqq 5,5-10$, and $>10$ respectively) and in the younger patients $(\mathrm{SIR}=$ 1.81 vs 1.61 for $<50$ and $\geqq 50$ respectively). The median overall survival for primary thyroid cancer patients was 23.28 years, but it was only 4.73 years for those who developed SPMs.

Conclusion: Thyroid cancer is associated with a 33\% risk increment of SPMs, which had a negative impact on survival. There are sites of SPMs in the Asian population that are distinctive from those in the Western population, suggesting that other genetic predisposition or environmental factors may play a role.
\end{abstract}

European Journal of Endocrinology 169 577-585

\section{Introduction}

Thyroid cancer accounts for $1-2 \%$ of all the cancers but involves more than 95\% malignancy of the endocrine system, excluding endocrine tumors of the gastro-enteropancreatic tract $(1,2)$. Even in a developed country like the USA, the age-adjusted incidence per 100000 has increased from 4.85 in 1975 to 12.98 in 2008 (3, 4), and this trend is also observed in other countries across Europe and worldwide $(5,6,7)$. In Taiwan, there were about 2000 new cases diagnosed in 2008, nearly a threefold increase in the incidence compared with that in 1995 (8). The increase may be due to the evolution of diagnostic scrutiny $(4,9)$, changes in histological criteria (4), various hormonal and environmental factors (10), increased BMI (11), and radiation or chemical exposure
$(12,13)$. The majority of newly diagnosed cases are early-stage, well-differentiated thyroid carcinomas, which carry a good prognosis with uncommon diseaserelated deaths $(4,14)$. Given the rising incidence of thyroid cancer and low disease-related mortality rate, the increased incidence of second primary malignancies (SPMs) among thyroid cancer survivors is expected.

Most studies on SPMs after primary thyroid cancer were conducted in the USA or Europe $(15,16,17,18$, $19,20,21,22)$. We found that some sites of SPMs differ from study to study. For example, the largest Surveillance, Epidemiology, and End Results (SEER)-based analysis from 30278 patients showed a significantly increased risk for cancers of the brain, breast, prostate, kidney, and salivary glands, Hodgkin lymphoma, leukemia, and myeloma as well as a significantly 
decreased risk for cancers of the head and neck (excluding thyroid and salivary gland), lung, esophagus, and bladder (20). A study carried out in a pooled cohort of 39002 patients at 13 population-based cancer registries in Europe, Canada, Australia, and Singapore showed that the risk of the following SPMs was significantly increased: salivary gland, pharynx, stomach, colon/rectum, brain, breast, prostate, kidney, soft tissue sarcoma, non-Hodgkin's lymphoma, leukemia, bone/joints, and adrenal gland (19). The discrepancy between SPMs in these studies could be attributed to geographical and ethnic heterogeneity.

The risk of SPMs after thyroid cancer in the Asian population has not been well documented; only a few institution-based small cohorts from Japan and Hong Kong were reported. Ishikawa et al. (23) conducted a retrospective study of 3321 operated thyroid cancer patients between 1946 and 1985 in their institution and found a significant elevated risk for SPM in the CNS and respiratory organs. Lang et al. $(24,25,26)$ has shown the increased risk of SPMs among 1106 thyroid cancer patients, but only the occurrence of SPMs in breast and stomach was statistically significant. There is a clear need for another large-scale epidemiological study. To achieve this objective, we conducted a retrospective population-based study using a database from the Taiwan Cancer Registry (TCR) that included a total of 19068 patients with an initial diagnosis of thyroid cancer during 1979-2006. To our knowledge, it is the largest scale study about SPMs after thyroid cancer in an Asian population.

\section{Subjects and methods}

\section{Data sources}

We determined second cancer incidences among 19874 patients with initial diagnoses of thyroid cancer who were reported to the TCR (http://www. tcr.cph.ntu. edu.tw) between 1st January 1979 and 31st December 2006. The TCR was founded in 1979 and financially supported by the National Department of Health with the aim of estimating the cancer incidence in Taiwan. The registry is assisted by a Cancer Registry Advisory Board, comprising expert members from various fields such as pathology, clinical oncology, radiation oncology, cancer registrar, and public health. It is a populationbased cancer registry that covered 22 million people in 2006. Hospitals with more than 50 beds are obligated to submit information on newly diagnosed cancer patients to the TCR, which reimburses the hospitals on the basis of numbers of cases reported in order to reduce the likelihood of under-reporting. The quality of TCR database was assured by two quality indexes: i) the DCO \% (percent of death certificate only cases) for all cancers ranges between 1.41 and $2.93 \%$ annually and ii) the $\mathrm{MV} \%$ (percent of morphological verification) for thyroid cancer (International Classification of Diseases, 9th revision (ICD-9): 193) ranges between 93.78 and $95.86 \%$ annually. All cancer registry databases in the TCR have been systematically converted to ICD-9 codes (27), and linked with death certificates from the National Death Database. Persons not identified by this process were therefore considered to be alive for the purpose of the current study (passive follow-up). Coding of multiple primaries followed the principles of the International Agency of Cancer Registries (IACR) and the International Agency for Research on Cancer (IARC) (28). Informed consent was not required because all registry records are anonymous and open to the public. To assess the age of onset accurately, estimate person-year follow-up, and minimize potentially unconfirmed cancer diagnosis in this study cohort, 806 patients were excluded from the analysis because they met one or more of the following criteria: i) missing birth dates or unknown gender (five cases); ii) missing last follow-up date or death status (385 cases); or iii) the period which is $<1$ month from initial diagnosis of primary cancer to the date of death or to the end of the study period (31st December 2006; 417 cases). As a result, a total of 19068 cases (4205 males and 14863 females) were included in the analysis.

\section{Statistical analysis}

To determine the excess of second malignancies after the diagnosis of primary thyroid cancer, we calculated the standardized incidence ratios (SIRs) (29) and the corresponding 95\% CIs for second cancers. SIRs were taken as the ratio of the observed number $(\mathrm{O})$ of second cancers to the expected number (E), which was obtained by assuming that these persons experienced the same cancer incidence as the corresponding general population. The number of person-years at risk was defined as the number of years from the date of initial primary cancer diagnosis to the date of death, date of last follow-up, date of diagnosis of a second primary cancer, or the end of the study period (31st December 2006), whichever came first. The person-years of observation for each gender, 5-year age group and 5- or 3-year period (1979-1983, 19841988, 1989-1993, 1994-1998, 1999-2003, and 2004-2006) were multiplied by the incidence rates of cancers for the Taiwanese population. The corresponding products were summed over all ages, gender, and calendar years to obtain the expected number of second cancers at each site. Ninety-five percent CIs of SIRs were based on the assumption of a Poisson distribution of second cancer cases, and an approximate $\chi^{2}$ test was used to test the difference between the two SIRs and the trend in the SIRs.

Cumulative incidence rates for occurrence of a second cancer were calculated in the survivors' cohort, with death treated as a competing risk according to the method described by Kalbfleisch \& Prentice (30). Briefly, this method allows for the fact that patients who die are no longer at risk for second cancers, so it differs from the cumulative incidence estimated by the Kaplan-Meier 
method, which treats competing events as censored at the time they occurred. Gray's test (31) was used to assess the statistical differences of cumulative incidence between genders. The survival curves of patients with second cancers were calculated by the Kaplan-Meier method and the differences between curves were presented by hazard ratio (HR) using the Cox proportional hazards model. All statistical tests were two-sided and $P$ values $<0.05$ were considered statistically significant.

\section{Results}

\section{Patient characteristics}

Of the total 19068 cases with thyroid cancer diagnosed as the first malignancy and complete data available for the analysis, 644 cases (3.38\%) developed at least a SPM during 134678 person-years of follow-up. The characteristics of the patient population are listed in Table 1. Within this cohort, the average follow-up time was 7.06 years, including 16717 cases $(87.67 \%)$ followed up for at least 1 year, 5491 cases $(28.80 \%)$ for 5-10 years, and 5307 cases $(27.83 \%)$ for $>10$ years. The mean age at diagnosis of first malignancy was 45.20 years. For those diagnosed as second primary cancers, the mean diagnosis age was 59.30 years with an average interval of 6.43 years between two primary cancers.

\section{Risk of second cancers stratified by site and gender}

SIRs and corresponding 95\% CIs were calculated. Irrespective of the site, the overall risk of developing a second primary cancer was significantly greater in both genders of patients with primary thyroid cancer than those in the general population (Table 2). A total of 644 subjects developed a subsequent cancer $(\mathrm{SIR}=1.33,95 \%$ CI 1.23-1.44): 201 males (SIR $=1.42,95 \% \quad$ CI 1.23-1.63) and 443 females (SIR $=1.29$, 95\% CI 1.18-1.42). In general, elevated risks with statistical significance were observed in eight second cancer sites: major salivary glands ( $\mathrm{SIR}=4.39,95 \%$ CI 1.60-9.56), nasopharynx $(\mathrm{SIR}=1.82,95 \%$ CI $1.08-2.88)$, lung $(\mathrm{SIR}=1.57,95 \%$ CI 1.25-1.95), thymus ( $\mathrm{SIR}=3.38$, 95\% CI 1.09-7.88), breast (females; SIR $=1.42,95 \% \mathrm{CI}$ 1.16-1.72), bladder ( $\mathrm{SIR}=1.76,95 \%$ CI 1.10-2.67), and brain (SIR $=4.02$, 95\% CI 2.29-6.52) and leukemia and lymphoma (SIR $=2.66,95 \%$ CI 1.77-3.84). There are 13 cases of second cancers classified in the category 'others', including small intestine, testis, bone, and some unspecified sites cancers.

\section{Risk of second cancers stratified by follow-up intervals}

To explore the latency of development of the cancers with elevated SIRs, the SIR estimates were stratified by
Table 1 Characteristics of the population-based cohort of 19068 patients diagnosed with thyroid cancer as the first primary cancer (ICD-9: 193) from 1979 to 2006.

\begin{tabular}{|c|c|c|c|}
\hline & All & Male & Female \\
\hline $\begin{array}{l}\text { No. with first } \\
\text { primary cancer }\end{array}$ & 19068 & 4205 & 14863 \\
\hline $\begin{array}{l}1979-1988 \\
\text { (10 years) }\end{array}$ & 1356 & 333 & 1023 \\
\hline $\begin{array}{r}1989-1998 \\
(10 \text { years })\end{array}$ & 7222 & 1545 & 5677 \\
\hline $\begin{array}{r}1999-2006 \\
\text { (8 years) }\end{array}$ & 10490 & 2327 & 8163 \\
\hline $\begin{array}{l}\text { No. who } \\
\text { developed a } \\
\text { SPM }(\%)^{\mathrm{a}}\end{array}$ & 644 (3.38\%) & 201 (4.78\%) & 443 (2.98\%) \\
\hline $\begin{array}{l}\text { Average ( } \pm \text { s.D.) } \\
\text { age at diagno- } \\
\text { sis of first } \\
\text { cancer (years) }\end{array}$ & $45.20 \pm 16.14$ & $48.72 \pm 17.26$ & $44.20 \pm 15.66$ \\
\hline $\begin{array}{l}\text { Average ( } \pm \text { s.D.) } \\
\text { age at diagno- } \\
\text { sis of a second } \\
\text { cancer (years) }\end{array}$ & $59.30 \pm 14.41$ & $60.80 \pm 15.74$ & $58.62 \pm 13.73$ \\
\hline $\begin{array}{l}\text { Average ( } \pm \text { S.D.) } \\
\text { interval } \\
\text { between the } \\
\text { first primary } \\
\text { and second } \\
\text { cancers } \\
\text { (years) }^{\mathrm{b}}\end{array}$ & $6.43 \pm 5.18$ & $5.60 \pm 4.72$ & $6.81 \pm 5.34$ \\
\hline $\begin{array}{l}\text { Average follow- } \\
\text { up (years) }\end{array}$ & $7.06 \pm 5.43$ & $6.26 \pm 5.35$ & $7.29 \pm 5.43$ \\
\hline
\end{tabular}

SPM, second primary cancer.

aPercentage out of number with first primary cancer.

'The case numbers are 644, 201, and 443 for 'all', 'male', and 'female' who developed a second cancer respectively.

interval since first diagnosis of thyroid cancer (Table 3). The entire follow-up period was divided into three consecutive intervals ( $\leq 5,5-10$, and $>10$ years). Overall, the risk for developing these second cancers was highest within 5 years of the diagnosis of thyroid cancer, then followed by 5-10 and $>10$ years with a significantly decreasing trend $(\mathrm{SIRs}=5.29,1.68$, and 0.68 for $\leq 5,5-10$ and $>10$ years respectively, and $P$ value $<0.001)$. Especially, the risks of developing second brain and thymus cancers were relatively high (SIRs $=21.16$ and 13.32 respectively). The risk of second cancers developing within 5-10 years was observed to be significant for lung cancer and leukemia and lymphoma only $($ SIRs $=1.76$ and 2.46 respectively).

\section{Age trend of second cancers}

To study the trend of the second cancers with age at initial diagnosis of the thyroid cancer, we stratified their SIRs according to two age groups $(<50$ and $\geq 50$; Table 4). The SIRs were significantly higher for younger patients diagnosed with second leukemia and lymphoma and bladder cancers $(P$ values $=0.005$ and 0.02 
Table 2 Observed and expected numbers of second primary cancers after diagnosis of an initial thyroid cancer (ICD-9: 193) in Taiwan from 1979 to 2006.

\begin{tabular}{|c|c|c|c|c|c|}
\hline $\begin{array}{l}\text { Second primary cancer site } \\
\text { (ICD-9 code) }\end{array}$ & Sex & 0 & $\mathbf{E}$ & $\operatorname{SIR}(\mathrm{O} / \mathrm{E})$ & $95 \% \mathrm{Cl}$ \\
\hline \multirow{3}{*}{$\begin{array}{l}\text { Oral/pharyngeal } \\
\quad(141,143-145,146,148-149)\end{array}$} & All & 14 & 17.41 & 0.80 & $0.44-1.35$ \\
\hline & $\mathrm{M}$ & 10 & 12.36 & 0.81 & $0.39-1.49$ \\
\hline & $\mathrm{F}$ & 4 & 5.04 & 0.79 & $0.21-2.03$ \\
\hline \multirow[t]{3}{*}{ Major salivary glands (142) } & All & 6 & 1.37 & 4.39 & $1.60-9.56$ \\
\hline & $\mathrm{M}$ & 2 & 0.37 & 5.38 & $0.60-19.43$ \\
\hline & $\mathrm{F}$ & 4 & 1.00 & 4.02 & $1.08-10.29$ \\
\hline \multirow[t]{3}{*}{ NPC (147) } & All & 18 & 9.87 & 1.82 & $1.08-2.88$ \\
\hline & $\mathrm{M}$ & 8 & 4.07 & 1.97 & $0.85-3.88$ \\
\hline & $\mathrm{F}$ & 10 & 5.80 & 1.72 & $0.82-3.17$ \\
\hline \multirow[t]{3}{*}{ Esophagus (150) } & All & 4 & 6.15 & 0.65 & $0.17-1.66$ \\
\hline & $\mathrm{M}$ & 3 & 4.80 & 0.62 & $0.13-1.82$ \\
\hline & $\mathrm{F}$ & 1 & 1.35 & 0.74 & $0.01-4.13$ \\
\hline \multirow[t]{3}{*}{ Stomach (151) } & All & 29 & 28.93 & 1.00 & $0.67-1.44$ \\
\hline & $M$ & 14 & 11.22 & 1.25 & $0.68-2.09$ \\
\hline & $\mathrm{F}$ & 15 & 17.71 & 0.85 & $0.47-1.40$ \\
\hline \multirow[t]{3}{*}{ Small intestine (12) } & All & 4 & 2.09 & 1.91 & $0.51-4.89$ \\
\hline & $\mathrm{M}$ & 1 & 0.66 & 1.51 & $0.02-8.41$ \\
\hline & $\mathrm{F}$ & 3 & 1.43 & 2.09 & $0.42-6.12$ \\
\hline \multirow[t]{3}{*}{ Colorectum $(153,154)$} & All & 81 & 66.09 & 1.23 & $0.97-1.52$ \\
\hline & M & 25 & 19.08 & 1.31 & $0.85-1.93$ \\
\hline & $\mathrm{F}$ & 56 & 47.01 & 1.19 & $0.90-1.55$ \\
\hline \multirow[t]{3}{*}{ Liver (155) } & All & 64 & 58.81 & 1.09 & $0.84-1.39$ \\
\hline & M & 35 & 25.69 & 1.36 & $0.95-1.89$ \\
\hline & $\mathrm{F}$ & 29 & 33.12 & 0.88 & $0.59-1.26$ \\
\hline \multirow[t]{3}{*}{ Gallbladder (156) } & All & 6 & 5.57 & 1.08 & $0.39-2.34$ \\
\hline & $\mathrm{M}$ & 2 & 1.45 & 1.37 & $0.15-4.96$ \\
\hline & $\mathrm{F}$ & 4 & 4.12 & 0.97 & $0.26-2.48$ \\
\hline \multirow[t]{3}{*}{ Pancreas (157) } & All & 9 & 8.29 & 1.09 & $0.50-2.06$ \\
\hline & $\mathrm{M}$ & 1 & 2.67 & 0.38 & $0.00-2.09$ \\
\hline & $\mathrm{F}$ & 8 & 5.62 & 1.42 & $0.61-2.81$ \\
\hline \multirow[t]{3}{*}{ Larynx (161) } & All & 6 & 2.49 & 2.41 & $0.88-5.25$ \\
\hline & M & 4 & 2.10 & 1.90 & $0.51-4.87$ \\
\hline & $\mathrm{F}$ & 2 & 0.38 & 5.21 & $0.58-18.79$ \\
\hline \multirow[t]{3}{*}{ Lung (162) } & All & 84 & 53.40 & 1.57 & $1.25-1.95$ \\
\hline & $\mathrm{M}$ & 27 & 21.82 & 1.24 & $0.82-1.80$ \\
\hline & $\mathrm{F}$ & 57 & 31.58 & 1.80 & $1.37-2.34$ \\
\hline \multirow[t]{3}{*}{ Thymus (164) } & All & 5 & 1.48 & 3.38 & $1.09-7.88$ \\
\hline & $\mathrm{M}$ & 3 & 0.41 & 7.31 & $1.47-21.36$ \\
\hline & $\mathrm{F}$ & 2 & 1.07 & 1.87 & $0.21-6.75$ \\
\hline \multirow[t]{3}{*}{ Bone (170) } & All & 1 & 0.86 & 1.16 & $0.02-6.45$ \\
\hline & $M$ & 1 & 0.21 & 4.79 & $0.06-26.65$ \\
\hline & $\mathrm{F}$ & 0 & 0.65 & 0 & NA \\
\hline \multirow[t]{3}{*}{ Sarcoma (171) } & All & 5 & 2.74 & 1.83 & $0.59-4.26$ \\
\hline & $\mathrm{M}$ & 1 & 0.74 & 1.35 & $0.02-7.51$ \\
\hline & $\mathrm{F}$ & 4 & 2.00 & 2.00 & $0.54-5.13$ \\
\hline Skin (173) & All & 21 & 14.88 & 1.41 & $0.87-2.16$ \\
\hline & $M$ & 3 & 4.11 & 0.73 & $0.15-2.13$ \\
\hline & $\mathrm{F}$ & 18 & 10.77 & 1.67 & $0.99-2.64$ \\
\hline Breast (female) (174) & $\mathrm{F}$ & 102 & 71.92 & 1.42 & $1.16-1.72$ \\
\hline Cervix uteri (180) & $\mathrm{F}$ & 28 & 39.46 & 0.71 & $0.47-1.03$ \\
\hline Corpus uteri (182) & $\mathrm{F}$ & 16 & 10.52 & 1.52 & $0.87-2.47$ \\
\hline Ovary (183) & $\mathrm{F}$ & 16 & 10.56 & 1.52 & $0.87-2.46$ \\
\hline Prostate gland (185) & $\mathrm{M}$ & 16 & 9.61 & 1.66 & $0.95-2.70$ \\
\hline Urinary bladder (188) & All & 22 & 12.48 & 1.76 & $1.10-2.67$ \\
\hline & $\mathrm{M}$ & 13 & 5.62 & 2.31 & $1.23-3.95$ \\
\hline & $\mathrm{F}$ & 9 & 6.86 & 1.31 & $0.60-2.49$ \\
\hline Kidney (189) & All & 20 & 12.92 & 1.55 & $0.94-2.39$ \\
\hline & $\mathrm{M}$ & 7 & 3.45 & 2.03 & $0.81-4.18$ \\
\hline & $\mathrm{F}$ & 13 & 9.47 & 1.37 & $0.73-2.35$ \\
\hline Brain (191) & All & 16 & 3.98 & 4.02 & $2.29-6.52$ \\
\hline & $M$ & 6 & 1.09 & 5.50 & $2.01-11.96$ \\
\hline & $\mathrm{F}$ & 10 & 2.89 & 3.46 & $1.66-6.36$ \\
\hline
\end{tabular}


Table 2 Continued

\begin{tabular}{lccccc}
\hline $\begin{array}{l}\text { Second primary cancer site } \\
\text { (ICD-9 code) }\end{array}$ & Sex & $\mathbf{O}$ & E & SIR (O/E) & $\mathbf{9 5 \% ~ C l ~}$ \\
\hline Lymph nodes (196) & All & 10 & 5.94 & 1.68 & $0.81-3.09$ \\
& M & 4 & 1.81 & 2.20 & $0.59-5.64$ \\
Leukemia and lymphoma & F & 6 & 4.13 & 1.45 & $0.53-3.16$ \\
& All & 28 & 10.53 & 2.66 & $1.77-3.84$ \\
Other sites & M & 9 & 3.22 & $\mathbf{2 . 8 0}$ & $1.28-5.31$ \\
& F & 19 & 7.31 & $\mathbf{2 . 6 0}$ & $1.56-4.06$ \\
Total & All & 13 & 15.53 & 0.84 & $0.45-1.43$ \\
& M & 6 & 4.67 & 1.28 & $0.47-2.80$ \\
& F & 7 & 10.86 & 0.64 & $0.26-1.33$ \\
& M & 644 & 483.90 & $\mathbf{1 . 3 3}$ & $1.23-1.44$ \\
& F & 443 & 141.25 & $\mathbf{1 . 4 2}$ & $1.23-1.63$ \\
& & & 342.65 & $\mathbf{1 . 2 9}$ & $1.18-1.42$ \\
\hline
\end{tabular}

Bold indicates statistical significance. SIR, standardized incidence ratio; $\mathrm{O}$, observed numbers of second cancers; $\mathrm{E}$, expected numbers of second cancers; NA, not accessible.

respectively). In contrast, the risk of developing a second lung cancer was slightly higher but insignificant for those diagnosed with thyroid cancer at age $\geq 50$ $(\mathrm{SIRs}=1.60$ vs $1.47, P$ value $=0.35)$. Similarly, both age groups for breast (females) cancer showed elevated risk, but these two SIRs were not significantly different $($ SIRs $=1.53$ vs $1.37, P$ value $=0.17)$.

\section{Cumulative incidence rates of all second cancers}

The estimated overall risk of developing a second cancer after primary thyroid cancer in the survivors' cohort was calculated with death treated as a competing risk. For all second cancers, the overall cumulative risks at 5, 10,15 , and 20 years after thyroid cancer were

Table 3 Risk for significant second primary cancers by follow-up interval after the diagnosis of thyroid cancer.

\begin{tabular}{|c|c|c|c|c|c|}
\hline $\begin{array}{l}\text { Second primary } \\
\text { cancer site } \\
\text { (ICD-9 code) }\end{array}$ & $\begin{array}{c}\text { Follow-up } \\
\text { interval } \\
\text { (years) }\end{array}$ & 0 & E & SIR (O/E) & $95 \% \mathrm{Cl}$ \\
\hline \multirow{3}{*}{$\begin{array}{l}\text { Major salivary } \\
\text { glands (142) }\end{array}$} & $\leq 5$ & 2 & 0.21 & 9.68 & $1.09-34.94$ \\
\hline & $5-10$ & 2 & 0.43 & 4.67 & $0.52-16.87$ \\
\hline & $>10$ & 2 & 0.73 & 2.73 & $0.31-9.86$ \\
\hline \multirow{3}{*}{ NPC (147) } & $\leq 5$ & 10 & 1.30 & 7.68 & $3.68-14.12$ \\
\hline & $5-10$ & 5 & 2.84 & 1.76 & $0.57-4.11$ \\
\hline & $>10$ & 3 & 5.73 & 0.52 & $0.11-1.53$ \\
\hline \multirow[t]{3}{*}{ Lung (162) } & $\leq 5$ & 37 & 9.24 & 4.00 & $2.82-5.52$ \\
\hline & $5-10$ & 29 & 16.52 & 1.76 & $1.18-2.52$ \\
\hline & $>10$ & 18 & 27.67 & 0.65 & $0.39-1.03$ \\
\hline \multirow[t]{3}{*}{ Thymus (164) } & $\leq 5$ & 3 & 0.23 & 13.32 & 2.68-38.91 \\
\hline & $5-10$ & 0 & 0.46 & 0 & NA \\
\hline & $>10$ & 2 & 0.80 & 2.51 & $0.28-9.07$ \\
\hline \multirow{3}{*}{$\begin{array}{l}\text { Leukemia } \\
\text { and lymphoma }\end{array}$} & $\leq 5$ & 14 & 1.72 & 8.16 & $4.46-13.69$ \\
\hline & $5-10$ & 8 & 3.26 & 2.46 & $1.06-4.84$ \\
\hline & $>10$ & 6 & 5.56 & 1.08 & $0.39-2.35$ \\
\hline \multirow{3}{*}{$\begin{array}{l}\text { Breast (females) } \\
\quad(174)\end{array}$} & $\leq 5$ & 45 & 10.13 & 4.44 & $3.24-5.95$ \\
\hline & $5-10$ & 32 & 22.76 & 1.41 & $0.96-1.98$ \\
\hline & $>10$ & 25 & 39.03 & 0.64 & $0.41-0.95$ \\
\hline \multirow{3}{*}{ Bladder (188) } & $\leq 5$ & 12 & 2.15 & 5.59 & $2.88-9.76$ \\
\hline & $5-10$ & 7 & 3.84 & 1.82 & $0.73-3.75$ \\
\hline & $>10$ & 3 & 6.50 & 0.46 & $0.09-1.35$ \\
\hline \multirow[t]{3}{*}{ Brain (191) } & $\leq 5$ & 12 & 0.57 & 21.16 & $10.92-36.96$ \\
\hline & $5-10$ & 3 & 1.22 & 2.46 & $0.49-7.18$ \\
\hline & $>10$ & 1 & 2.20 & 0.46 & $0.01-2.53$ \\
\hline \multirow[t]{3}{*}{ Total } & $\leq 5$ & 135 & 25.53 & 5.29 & $4.43-6.26$ \\
\hline & $5-10$ & 86 & 51.33 & 1.68 & $1.34-2.07$ \\
\hline & $>10$ & 60 & 88.22 & 0.68 & $0.52-0.88$ \\
\hline
\end{tabular}

Bold indicates statistical significance. SIR, standardized incidence ratio; $\mathrm{O}$, observed numbers of second cancers; $\mathrm{E}$, expected numbers of second cancers; NA, not accessible. 
Table 4 Risk for significant second cancers by age at initial onset among 19028 patients with thyroid cancer.

\begin{tabular}{|c|c|c|c|c|c|}
\hline $\begin{array}{l}\text { Second primary } \\
\text { cancer site } \\
\text { (ICD-9 code) }\end{array}$ & Age (years) & 0 & E & SIR (O/E) & $95 \% \mathrm{Cl}$ \\
\hline \multirow{2}{*}{$\begin{array}{l}\text { Major salivary } \\
\text { glands (142) }\end{array}$} & $<50$ & 5 & 0.72 & 6.91 & $2.23-16.12$ \\
\hline & $\geq 50$ & 1 & 0.64 & 1.55 & $0.02-8.65$ \\
\hline \multirow[t]{2}{*}{ NPC (147) } & $<50$ & 10 & 6.23 & 1.61 & $0.77-2.95$ \\
\hline & $\geq 50$ & 8 & 3.64 & 2.20 & $0.95-4.33$ \\
\hline \multirow[t]{2}{*}{ Lung (162) } & $<50$ & 17 & 11.58 & 1.47 & $0.85-2.35$ \\
\hline & $\geq 50$ & 67 & 41.82 & 1.60 & $1.24-2.03$ \\
\hline \multirow[t]{2}{*}{ Thymus (164) } & $<50$ & 2 & 0.76 & 2.65 & $0.30-9.56$ \\
\hline & $\geq 50$ & 3 & 0.72 & 4.14 & $0.83-12.10$ \\
\hline \multirow{2}{*}{$\begin{array}{l}\text { Leukemia and } \\
\text { lymphoma }\end{array}$} & $<50$ & 18 & 3.90 & 4.62 & $2.73-7.30$ \\
\hline & $\geq 50$ & 10 & 6.63 & 1.51 & $0.72-2.77$ \\
\hline \multirow{2}{*}{$\begin{array}{l}\text { Breast (females) } \\
\quad(174)\end{array}$} & $<50$ & 67 & 49.03 & 1.37 & $1.06-1.74$ \\
\hline & $\geq 50$ & 35 & 22.89 & 1.53 & $1.06-2.13$ \\
\hline \multirow[t]{2}{*}{ Bladder (188) } & $<50$ & 9 & 2.39 & 3.77 & $1.72-7.16$ \\
\hline & $\geq 50$ & 13 & 10.09 & 1.29 & $0.69-2.20$ \\
\hline \multirow[t]{2}{*}{ Brain (191) } & $<50$ & 11 & 2.05 & 5.37 & $2.68-9.62$ \\
\hline & $\geq 50$ & 5 & 1.94 & 2.58 & $0.83-6.02$ \\
\hline \multirow[t]{2}{*}{ Total } & $<50$ & 139 & 76.65 & 1.81 & $1.52-2.14$ \\
\hline & $\geq 50$ & 142 & 88.39 & 1.61 & $1.35-1.89$ \\
\hline
\end{tabular}

Bold indicates statistical significance. SIR, standardized incidence ratio; O, observed numbers of second cancers; E, expected numbers of second cancers.

estimated to be $1.88,3.79,5.89$, and $8.10 \%$ respectively. The cumulative incidences in males were higher than that in females over time, indicating that both genders were not at equivalent risk for all second cancers ( $P$ value $<0.001$; Fig. 1$)$.

\section{Overall survival of the thyroid cancer patients}

The overall 5 -year survival rate $( \pm$ s.E.M. $)$ for all thyroid cancer patients in our study was $89.70 \%( \pm 0.2 \%)$ with a median survival of $23.28( \pm 0.17)$ years. Both age at onset and gender were associated with survival. The Cox proportional hazards model showed that the males had a worse survival than the females $(\mathrm{HR}=1.73, P$ value $<0.001,95 \%$ CI $1.60-1.87$; Fig. 2), and the patient with a diagnosis of thyroid cancer while older had shorter survival $(\mathrm{HR}=1.089, P$ value $<0.001,95 \%$ CI $1.086-1.091)$.

\section{Survival time after second cancers}

The median survival $( \pm$ s.E.M. $)$ after developing a second cancer was $4.73( \pm 0.58)$ years. The survival curve after the diagnosis of the second cancers was calculated by the Kaplan-Meier method and the results suggest that females lived much longer than males $(\mathrm{HR}=1.69$, $P$ value $<0.001,95 \%$ CI 1.35-2.12; Fig. 3). The 5-year survival rates $( \pm$ s.E.M. $)$ in males and in females were $36.90 \%( \pm 3.7 \%)$ and $53.60 \%( \pm 2.7 \%)$ respectively.

\section{Discussion}

In Taiwan, more than $90 \%$ of thyroid cancer patients are papillary and follicular type cases (8). The data collected by the SEER program of the National Cancer Institute showed that the 10-year survival rate of differentiated thyroid cancer exceeds $90 \%$ (20). In our cohort, the median survival time of all patients with thyroid cancer is 23.28 years. The disease therefore has a very good prognosis. However, SPMs adversely impact the survival of thyroid cancer patients, with a median survival 4.73 years, suggesting a specific surveillance for the occurrence of second cancers is important in order to improve total mortality.

The female-to-male ratio of thyroid cancer patients was 3.53, consistent with the SEER database including a total of 30278 patients and nearly 30 years of follow-up (20). However, the risk of SPMs is higher in males than in females ( $\mathrm{SIR}=1.42$ vs 1.29 ). For specific cancers, males had an increased risk of developing secondary thymus, urinary bladder, brain cancers, and leukemia and

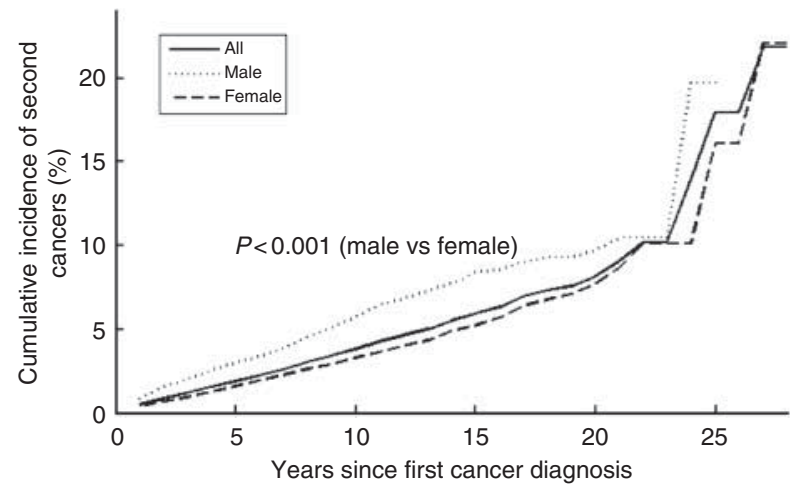

Figure 1 Cumulative incidences of second cancers for patients with initial diagnosis of thyroid cancer stratified by gender. 


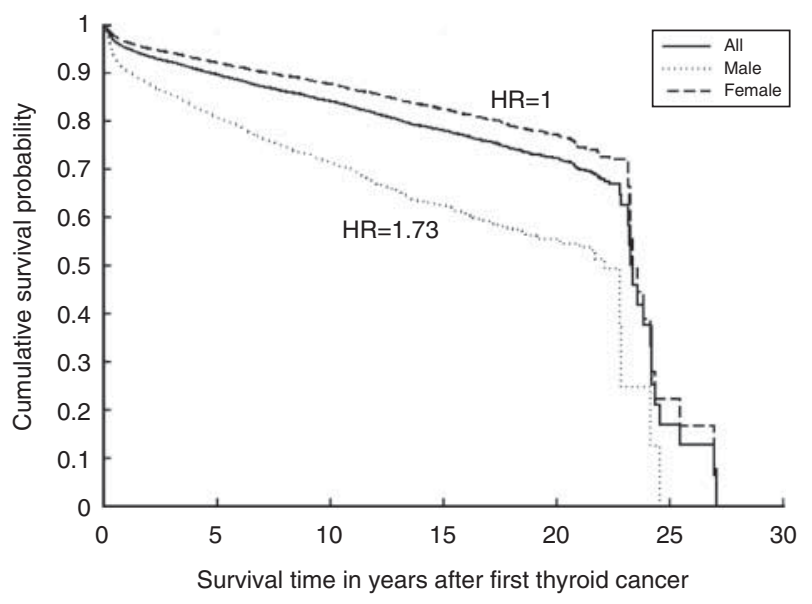

Figure 2 Survival curves of all the patients after thyroid cancer stratified by gender.

lymphoma. Females had increased risk for secondary salivary gland, lung, breast, and brain cancers and leukemia and lymphoma. Although many second cancers are similar, there are notable differences between our cohort and SEER. A decreased risk for cancers of the head and neck (except salivary gland), lung and bladder was reported in SEER. On the other hand, we found an increased risk of nasopharyngeal carcinoma $(\mathrm{SIR}=1.82)$, lung $(\mathrm{SIR}=1.57)$, and urinary bladder $(\mathrm{SIR}=1.76)$ cancers, suggesting that genetic predisposition and environmental risk factors may play a role. For example, lung cancer in Asian countries is very different from that in Western populations with respect to mutated epidermal growth factor receptor gene, predominant in females and non-smokers, and adenocaricnomas cell-type. EpsteinBarr virus infection is a unique environmental factor for nasopharygeal carcinoma which is rare in most parts of the world, but outstandingly prevalent in South-East Asia.

Our study has shown that in people with a primary thyroid cancer, there is a 33\% increased risk of developing a second primary cancer in comparison with the general population. In keeping with SEER as well as the other large-scale study by Sandeep et al. including 39002 patients from 13 population-based cancer registries in Europe, Canada, Australia, and Singapore $(19,20)$, we also found the increased incidence in secondary salivary gland, breast (females), and brain cancers and leukemia. These second primary cancers may occur because of shared environmental or genetic risks or may be therapy related. The mainstay of treatment for differentiated thyroid cancer in Taiwan is nearly total thyroidectomy and postoperative radioactive iodine (RAI) treatment if extensive disease (32). External radiotherapy is not a routine practice and was reserved only for postoperatively residual disease in the neck but with inadequate radioiodine uptake or for cases with loco-regional recurrence. RAI is known to be excreted in breast milk, saliva, stool, and urine, which might account for the risk of salivary gland, breast, and kidney cancers. However, this speculation is contradictory to the findings by SEER that both the increased risk of breast and kidney cancers was statistically equivalent in both the irradiated and non-irradiated cohorts. Besides, there was no increased risk of colorectal and urinary bladder cancers in SEER. In contrast to SEER, we found an increased risk in urinary bladder but not kidney in our cohort. Therefore, the association of RAI treatment and risk of SPMs following thyroid cancer remains widely debated $(15,16,17,18,20,24$, $33,34)$. A meta-analysis including two major studies from USA and Europe draws the conclusion that RAI slightly increased the relative risk of SPMs in thyroid cancer survivors but only secondary leukemia is most relevant (35). Furthermore, we and the SEER group (20) have both found that the risk for developing these second cancers was highest within the first 5 years after diagnosis of thyroid cancer. Considering the long latency required for carcinogenesis, that excess risk of SPMs occurring within a short period after the first cancer argues against the hypothesis of the first primary treatment as the only initiator for the second cancer. This observation suggests other factors aside from therapy, such as heritable factors, may influence second cancer risk. For example, persons with rare inherited cancer susceptibility genes and those with genetic polymorphisms of some DNA-repair enzyme genes are at a high risk of second cancers $(36,37,38)$. Also, we could not exclude an other possibility that the excess risk within the first 5 years might be due to more frequent examinations (surveillance bias).

The misclassification of metastases in some anatomic sites such as bone, brain, liver, and lung as new primary cancers is always an inherent concern in most population-based studies. Coding of multiple primaries in the TCR rules followed the principles of the IACR and the IARC. The most common metastatic sites from thyroid cancers are lung, bone, and brain. Among 19068 thyroid cancer patients, there were 644

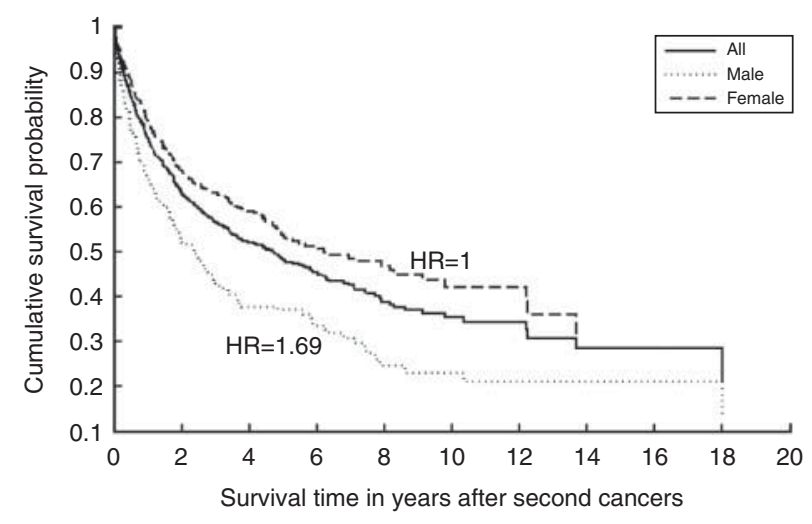

Figure 3 Survival curves of all the patients after second cancers stratified by gender. 
patients who developed SPMs (only one bone, 16 brain, and 84 lung cancers). The characteristic radiographic image of lung metastasis from primary thyroid makes it distinguishable from primary lung cancer. Considering the incidences of thyroid cancer metastasizing to these distant sites are much higher than these numbers, we speculate that the coding of the TCR database is reliable.

The strengths of this study include a large population database from a nation-wide and government-supported cancer registry in an Asian population over a 28-year period. However, the major limitation in our study is the lack of some information such as RAI exposure history and subtypes of thyroid cancer that might have an impact on the incidences of some SPMs. We have confirmed thyroid cancer is associated with a 33\% increase in risk of second malignancies, which had a negative impact on the survival of patients. Nevertheless, these results did not allow the clinician to make a causal link between thyroid cancer and the occurrence of SPMs. There are some sites of SPMs distinctive from those in the Western population, suggesting that other genetic predisposition or environmental risk factors may play a role.

\section{Declaration of interest}

The authors declare that there is no conflict of interest that could be perceived as prejudicing the impartiality of the research reported.

\section{Funding}

This work was supported by National Science Council grants 98-2314-B-182-029-MY2 and grants CMRPG 690051 from the Chang-Gung Memorial Hospital, Chia-Yi, Taiwan.

\section{Author contribution statement}

C-H Lu and K-D Lee conceived the study design and performed data collection. M-C Chen contributed in statistical analysis. C-H Lu, K-D Lee, and $\mathrm{M}-\mathrm{C}$ Chen wrote the manuscript with the input of P-T Chen, C-C Chen, F-C Kuan, C-E Huang, and M-F Chen. All authors read and approved the final manuscript.

\section{Acknowledgements}

The authors thank all the staff in the Taiwan Cancer Registry and Bureau of Health Promotion, National Department of Health, Taiwan, ROC.

\section{References}

1 Hundahl SA, Fleming ID, Fremgen AM \& Menck HR. A National Cancer Data Base report on 53,856 cases of thyroid carcinoma treated in the U.S., 1985-1995. Cancer 199883 2638-2648. (doi:10.1002/(SICI)1097-0142(19981215)83:12<2638::AIDCNCR31>3.0.CO;2-1)

2 Jemal A, Siegel R, Xu J \& Ward E. Cancer Statistics, 2010. CA: A Cancer Journal for Clinicians 201060 277-300. (doi:10.3322/ caac.20073)

3 Howlader N, Noone AM, Krapcho M, Neyman N, Aminou R, Waldron W, Altekruse SF, Kosary CL, Ruhl J, Tatalovich Z et al. (eds). In SEER Cancer Statistics Review, 1975-2008. Bethesda, MD:
National Cancer Institute (http://seer.cancer.gov/csr/1975_2008/, based on November 2010 SEER data submission, posted to the SEER web site), 2011.

4 Davies L \& Welch HG. Increasing incidence of thyroid cancer in the United States, 1973-2002. Journal of the American Medical Association 2006295 2164-2167. (doi:10.1001/jama.295.18.2164)

5 Ferlay J, Bray F, Pisani P \& Parkin DM. In GLOBOCAN 2000: Cancer Incidence, Mortality and Prevalence Worldwide, v 1.0. IARC Cancer Base No. 5. Lyon: IARC Press (available at: http://wwwdep.iarc.fr/ globocan/globocan.html).

6 Kilfoy BA, Zheng T, Holford TR, Han X, Ward MH, Sjodin A, Zhang Y, Bai Y, Zhu C, Guo GL et al. International patterns and trends in thyroid cancer incidence, 1973-2002. Cancer Causes $\mathcal{E}$ Control 200920 525-531. (doi:10.1007/s10552-008-9260-4)

7 Burgess JR. Temporal trends for thyroid carcinoma in Australia: an increasing incidence of papillary thyroid cancer (1982-1997). Thyroid 200012 141-149. (doi:10.1089/1050725027535 22374)

8 Bureau of Health Promotion, Department of Health, Taiwan (available at: http://www.bhp.doh.gov.tw/BHPNET/Portal/Statistics.aspx).

9 Verkooijen HM, Fioretta G, Pache JC, Franceschi S, Raymond L, Schubert H \& Bouchardy C. Diagnostic changes as a reason for the increase in papillary thyroid cancer incidence in Geneva, Switzerland. Cancer Causes \& Control 200314 13-17. (doi:10. 1023/A:1022593923603)

10 La Vecchia C, Ron E, Franceschi S, Dal Maso L, Mark SD, Chatenoud L, Braga C, Preston-Martin S, McTiernan A, Kolonel L et al. A pooled analysis of case-control studies of thyroid cancer. III. Oral contraceptives, menopausal replacement therapy and other female hormones. Cancer Causes \& Control 199910 157-166. (doi:10.1023/A:1008832513932)

11 Clavel-Chapelon F, Guillas G, Tondeur L, Kernaleguen C \& Boutron-Ruault MC. Risk of differentiated thyroid cancer in relation to adult weight, height, and body shape over life: the French E3N cohort. International Journal of Cancer 2010126 2984-2990. (doi:10.1002/ijc.25066)

12 Ron E, Lubin JH, Shore RE, Mabuchi K, Modan B, Pottern LM, Schneider AB, Tucker MA \& Boice JD Jr. Thyroid cancer after exposure to external radiation: a pooled analysis of seven studies. Radiation Research 1995141 259-277. (doi:10.2307/3579003)

13 Zuurbier M, Leijs M, Schoeters G, ten Tusscher G \& Koppe JG. Children's exposure to polybrominated diphenyl ethers. Acta Paediatrica. Supplementum 200695 65-70. (doi:10.1080/ 08035320600886299)

14 Colonna M, Grande E, Jonasson JG \& Eurocare Working Group. Variation in relative survival of thyroid cancers in Europe: results from the analysis on 21 countries over the period 1983-1994 (EUROCARE-3 study). European Journal of Cancer $2006 \mathbf{4 2}$ 2598-2608. (doi:10.1016/j.ejca.2006.04.026)

15 Rubino C, de Vathaire F, Dottorini ME, Hall P, Schvartz C, Couette JE, Dondon MG, Abbas MT, Langlois C \& Schlumberger M. Second primary malignancies in thyroid cancer patients. British Journal of Cancer 200389 1638-1644. (doi:10.1038/sj.bjc. 6601319)

16 Berthe E, Henry-Amar M, Michels JJ, Rame JP, Berthet P, Babin E, Icard P, Samama G, Galateau-Salle F, Mahoudeau J et al. Risk of second primary cancer following differentiated thyroid cancer. European Journal of Nuclear Medicine and Molecular Imaging 2004 31 685-691. (doi:10.1007/s00259-003-1448-y)

17 Ronckers CM, McCarron P \& Ron E. Thyroid cancer and multiple tumors in the SEER cancer registries. International Journal of Cancer 2005117 281-288. (doi:10.1002/ijc.21064)

18 Verkooijen RB, Smit JW, Romijn JA \& Stokkel MP. The incidence of second primary tumors in thyroid cancer patients is increased, but not related to treatment of thyroid cancer. European Journal of Endocrinology 2006155 801-806. (doi:10.1530/eje.1.02300)

19 Sandeep TC, Strachan MW, Reynolds RM, Brewster DH, Scelo G, Pukkala E, Hemminiki K, Anderson A, Tracey E, Friis S et al. Second primary cancers in thyroid cancer patients: a multinational record linkage study. Journal of Clinical Endocrinology and Metabolism 200691 1819-1825. (doi:10.1210/jc.2005-2009) 
20 Brown AP, Chen J, Hitchcock YJ, Szabo A, Shrieve DC \& Tward JD. The risk of second primary malignancies up to three decades after the treatment of differentiated thyroid cancer. Journal of Clinical Endocrinology and Metabolism 200893 504-515. (doi:10.1210/ jc.2007-1154)

21 Berrington de Gonzalez A, Curtis RE, Kry SF, Glibert E, Lamart S, Berg CD, Stovall M \& Ron E. Proportion of second cancers attributable to radiotherapy treatment in adults: a cohort study in the SEER cancer registries. Lancet Oncology 201212 353-360. (doi:10.1016/S1470-2045(11)70061-4)

22 Kim C, Bi X, Pan D, Chen Y, Carling T, Ma S, Udelsman R \& Zhang Y. Risk of second cancer after diagnosis of thyroid cancer primary is elevated in microcarcinoma. Thyroid 201323 575-582. (doi:10.1089/thy.2011.0406)

23 Ishikawa K, Noguchi S, Tanaka K, Fukuda A \& Hirohata T. Second primary neoplasms in thyroid cancer patients. Japanese Journal of Cancer Research 199687 232-239. (doi:10.1111/j.1349-7006. 1996.tb00211.x)

24 Lang BH, Wong IO, Wong KP, Cowling BJ \& Wan KY. Risk of second primary malignancy in differentiated thyroid carcinoma treated with radioactive iodine therapy. Surgery $2012 \mathbf{1 5 1}$ 844-850. (doi:10.1016/j.surg.2011.12.019)

25 Lang BH, Lo CY, Wong IO \& Cowling BJ. Impact of second primary malignancy on outcome of differentiated thyroid carcinoma. Surgery 2010148 1191-1196. (doi:10.1016/j.surg.2010.09.022)

26 Lang BH \& Wong KP. Risk factors for nonsynchronous second primary malignancy and related death in patients with differentiated thyroid carcinoma. Annals of Surgical Oncology 201118 3559-3565. (doi:10.1245/s10434-011-1777-1)

27 Slee VN. The International Classification of Diseases: ninth revision (ICD-9). Annals of Internal Medicine 1978 88 424-426. (doi:10.7326/0003-4819-88-3-424)

28 Muir CS \& Percy C. Cancer registration: principles and methods. Classification and coding of neoplasms. IARC Scientific Publications $19919564-81$.

29 Breslow NE \& Day NE. Statistical methods in cancer research. Volume II - the design and analysis of cohort studies. IARC Scientific Publications 198782 1-406.
30 Kalbfleisch J \& Prentice PR. In The Analysis of Failure Time Data, vol 2, 2nd edn, pp 203-215. New York: John Wiley \& Sons, 2002.

31 Gray R. A class of K-sample tests for comparing the cumulative incidence of a competing risk. Annals of Statistics $1988 \mathbf{1 6}$ 1141-1154. (doi:10.1214/aos/1176350951)

32 Lin JD, Lin KJ, Chao TC, Hseuh C, Tsang NM \& Huang BY. Clinical presentations of thyroid cancer patients with multiple primary cancers. Journal of Endocrinological Investigation $20113 \mathbf{3 4}$ 824-830. (doi:10.3275/7747)

33 Adjadj E, Rubino C, Shamsaldim A, Le MG, Schlumberger M \& de Vathaire F. The risk of multiple primary breast and thyroid carcinomas. Cancer 200398 1309-1317. (doi:10.1002/cncr. 11626)

34 Chuang SC, Hashibe M, Yu GP, Le AD, Cao W, Hurwitz EL, Rao JY, Neugut AI \& Zhang ZF. Radiotherapy for primary thyroid cancer as a risk factor for second primary. Cancer Letters 2006238 42-52. (doi:10.1016/j.canlet.2005.06.015)

35 Sawka AM, Thabane L, Parlea L, Ibrahim-Zada I, Tsang RW, Brierley JD, Straus S, Ezzat S \& Goldstein DP. Second primary malignancy after radioactive iodine treatment for thyroid cancer: a systemic review and meta-analysis. Thyroid 200919 451-457. (doi:10.1089/thy.2008.0392)

36 Gal TJ, Huang WY, Chen C, Hayes RB \& Schwartz SM. DNA repair gene polymorphisms and risk of second primary neoplasms and mortality in oral cancer patients. Laryngoscope $2005 \mathbf{1 1 5}$ 2221-2231. (doi:10.1097/01.mlg.0000183736.96004.f7)

37 Erčulj N, Faganel Kotnik B, Debeljak M, Jazbec J \& Dolžan V. DNA repair polymorphisms influence the risk of second neoplasm after treatment of childhood acute lymphoblastic leukemia. Journal of Cancer Research and Clinical Oncology 2012138 1919-1930. (doi:10.1007/s00432-012-1265-4)

38 Feller L \& Lemmer J. New ‘second primary' cancers. SADJ 201267 175-178.

Received 16 April 2013

Revised version received 6 August 2013

Accepted 12 August 2013 